\title{
More young adults accidentally pregnant; neither timed nor wanted: evidence from Southwest Ethiopia
}

\author{
Sharew Mulugeta ${ }^{1}$, Tizta Tilahun ${ }^{2 *}$, Bitiya Admasu ${ }^{3}$
}

\begin{abstract}
${ }^{1}$ Department of Public Health, College of Medicine and Health Sciences, Mizan-Tepi University, Mizan, Ethiopia ${ }^{2}$ Population Dynamics and Reproductive Health Unit, Africa Population and Health Research Center, Nairobi, Kenya ${ }^{3}$ Department of Population and Family Health, Jimma University, Jimma, Ethiopia
\end{abstract}

Received: 10 June 2018

Accepted: 03 July 2018

\author{
*Correspondence: \\ Dr. Tizta Tilahun, \\ E-mail: ttilahun@aphrc.org
}

Copyright: (c) the author(s), publisher and licensee Medip Academy. This is an open-access article distributed under the terms of the Creative Commons Attribution Non-Commercial License, which permits unrestricted non-commercial use, distribution, and reproduction in any medium, provided the original work is properly cited.

\begin{abstract}
Background: In the resource-poor setting, unintended pregnancy is exacerbated by several factors that result in high maternal and newborn deaths. Given the considerable gap between actual and wanted fertility rates in Ethiopia, preventing unintended pregnancy can play a role in reducing complications, morbidity, and mortality. The purpose of this study was to determine unintended pregnancy and its correlates among ever pregnant women in Bitta woreda, Southwest Ethiopia.

Methods: Quantitative data from a community-based cross-sectional study among 770 ever- pregnant women (15-49 years) were employed. A random selection using multistage sampling technique was exercised to select study participants. Logistic regression models were used to asses factors associated with unintended pregnancy.

Results: In the study area nearly, thirty-seven percent of women have experienced an unintended pregnancy: mistimed (26\%) and unwanted (11\%). Three percent of the respondents had a faced an induced abortion. A relatively higher proportion of women aged 26-29 years reported experiencing unwanted and mistimed pregnancies. Women who traveled a longer distance (more than an hour) to family planning service area were more likely to face unintended pregnancy $(\mathrm{AOR}=2.23(1.37-3.63)$ ). A woman who had more than five parity were more likely to experience unintended pregnancy 5.52(2.50-12.20).

Conclusions: The unintended pregnancy remains higher in the study area which is more than the national average. Existing unintended pregnancy among young women urges family planning providers to deliver youth-inclusive family planning programs.
\end{abstract}

Keywords: Ever pregnant, Mistimed pregnancy, Unwanted pregnancy Unintended pregnancy

\section{INTRODUCTION}

The concept of unintended pregnancy has been essential to demographers in seeking to understand fertility, unwanted pregnancy and how to promote woman's ability to determine whether and when to have children. ${ }^{1}$ Research findings highlight unintended pregnancy as a leading cause of unsafe abortion and maternal mortality and morbidity. ${ }^{2,3}$ Despite a decrease in maternal mortality in the world by $43 \%$ from approximately 532,000 deaths in 1990 to an estimated 303000 deaths in 2015, in developing countries, it is a major public health issue. ${ }^{4}$ In Africa, over $40 \%$ of the total maternal deaths are occurred due to unsafe abortion, making it the leading cause of maternal mortality. ${ }^{5}$ Developing countries take a large share of women with unintended pregnancy, account for approximately 99\% (302 000) of the global maternal deaths, sub-Saharan Africa alone accounting for roughly $66 \%$ (201 000) in 2015. ${ }^{4}$ An unintended 
pregnancy could be either mistimed (they occurred earlier than desired) or unwanted (they occurred when no children or no more children were desired) at the time of conception. ${ }^{1}$ Studies show women who experience an unintended pregnancy are more likely to seek an abortion, and nearly half of all unintended pregnancies end in induced abortion, which in many cases will be illegal and unsafe in sub-Saharan Africa. ${ }^{6}$

In Ethiopia, the prevalence of unintended pregnancy is $29 \%$ with a maternal mortality ratio of 673 deaths per 100,000 live births in $2014 .{ }^{7}$ A large proportion of these deaths result from the unsafe abortion performed owing to unwanted pregnancies. A nationally representative survey conducted in 2008 appraised, 382,000 induced abortions were executed and 52,600 women were treated for complications of abortion. ${ }^{8}$ The level of unwanted fertility is a sign of the existence of unintended pregnancy, the country has the total fertility rate (TFR) which is 1.8 children greater than the total wanted fertility rate (TWFR). It displays the total fertility rate is nearly $39 \%$ higher than it would be if unwanted births were avoided. ${ }^{9,10}$ A large number of studies on determinants of unintended pregnancy have investigated also the potential effects women experience. Findings reported that women's autonomy, partner communication about family planning, desire for children, ideal number of children, family planning health worker visit, travel time to the nearest family planning service area, and exposure to mass media were among the factors that significantly associated with unintended pregnancy. ${ }^{11-15}$ On the other side, a study reveals the age of respondents, household economic status, and educational level, were among the factors that significantly associated with unintended pregnancy. ${ }^{11}$ Regards the effects of encountering unintended pregnancy, a study illustrates women with unwanted pregnancy had almost twice as likely undergoing depressive symptoms compared with women with a wanted pregnancy. ${ }^{12}$

From the three successive surveys, it is reported that unwanted pregnancies are decreasing; $17 \%, 16 \%$ and $9 \%$ in 2000, 2005 and 2011 respectively in Ethiopia. ${ }^{10,14,16}$ However, the percentage of births that were wanted later (mistimed) remained stable over the years in the range of 19-20\%. ${ }^{10,14,16}$ This calls for the investigation of factors for unintended pregnancies to reduce its occurrence and act for prevention. Based on evidence demonstrated above this paper entails to examining unintended pregnancy and associated factors among ever-pregnant women. It is conducted in 2015, in an urban and rural area of Bitta woreda, Southwest, Ethiopia.

\section{METHODS}

This paper used a quantitative data from a community based cross-sectional study conducted in Bita district, Ethiopia. Bita district is one of the ten districts in the zone located $70 \mathrm{Kms}$ from the zonal capital Bonga, Southern Nations, Nationalities, and people's (SNNP).
The district has two urban and 24 rural kebeles with the total estimated population projection for the year 2007 is to be 93,585 and females accounted $50.5 \%(47,260)$ of the total population. ${ }^{17}$ The research was based on women who had ever been pregnant or currently pregnant during this survey data collected from the selected kebeles (small districts in the administrative structure of Ethiopia).

\section{Inclusion criteria}

- $\quad$ Age group 15-49 years

- Who had ever been pregnant for at least once within the past five years preceding the survey

- Currently pregnant and who lived in the study for at least six months prior to the day of the survey.

\section{Exclusion criteria}

Those who were seriously ill and unable to communicate at the time of data collection.

The sample size was determined using single population proportion formula by considering the following assumptions: the prevalence of unintended pregnancy from a study in South West Ethiopia to be 35\%; 5\% margin of error and $95 \%$ confidence level of certainty (1.96). ${ }^{18}$ Accounting the $10 \%$ non-response rate of 35 and design effect of 2 , the total sample size attained was $770 .{ }^{19}$

Regarding sampling procedure, the study area has two urban and twenty-four rural kebeles. For this study one urban kebele selected from the two by simple random sampling (lottery method) and eight rural kebeles were selected among the 24 kebeles by simple random sampling, a total of 9 kebeles were included in the study. Census was conducted based on the inclusion criteria in selected kebeles, the number of women was allocated in to kebeles by proportionally allocating to their population size based on the sample size, women from census in each kebele were registered and given codes using the list of the census, then required numbers of women included in the study were selected by SPSS V.20 for random selection.

Data were collected using a structured interview questionnaire and administered by eight data collectors, from February 10-24, 2015. Training was given to data collectors and the supervisors on the questionnaire, approach to the interviewees, details of interviewing techniques, respect and maintaining privacy and confidentiality of the respondents. The questionnaire was pre-tested in the area which has the same set up as the study site with $5 \%$ (thirty-nine mothers) and important revisions were done based on the feedback. The questionnaire was developed using a tool that was applied in different studies related to unintended pregnancy previously. ${ }^{13}$ The questionnaire was translated from English to the local language and back to English to 
assure consistency. The collected data were checked for completeness, accuracy, clarity, and consistency.

In this study, women's experience of unintended pregnancy in the past five years prior to the survey is the dependent variable. It is a retrospective measure of a woman's feeling about her pregnancy at the time that she learned she was pregnant. Unintended pregnancy was assessed as either mistimed or unwanted pregnancy for those who were pregnant during this survey data collection. The question was "At the time you became pregnant did you want to become pregnant then, did you want to wait until later, or did you not want to have any (more) children at all".

Women who had had a birth in the five years prior to the survey but were not pregnant at the time of the survey, were asked: "At the time you became pregnant your most recent baby", did you want to become pregnant then, did you want to wait until later, or did you not want to have any (more) children at all?. The independent variables include women's education, age, marital status, economic status, place of residence, partner communication about family planning, women's autonomy, religion, parity, ideal number of children, exposure to media, travel time to family planning service, knowledge of any modern family planning, family planning practice identified a priori from reviewed literatures. ${ }^{10,18,19}$

\section{Statistical analysis}

Data were entered using Epidata 3.1 and analyzed by STATA software version 13. Running descriptive results; computing cross-tabulations and bivariate analysis, and lastly multivariate analysis were performed and P-value less than 0.05 taken as statistically significant.

\section{RESULTS}

A total of 755 women were interviewed and making the response $98 \%$. The prevalence of unintended pregnancy in this study was $36.5 \%$. The percentage of pregnancies that were mistimed and unwanted were $26 \%$ and $10.5 \%$ respectively.

Having a mean \pm SD age of the respondents was $25.8 \pm 5.3$ years, the majority of the respondents aged 30-34 years (Table 1). Regarding residence, about $87 \%$ of the participants were living in a rural setting. Nearly eighty percent of the women $606(80.3 \%$ ) were currently married with mean \pm SD ages at marriage of $28.0 \pm 5.9$ years (Table 1).

Fifty-six percent of women had no any formal education, $444(58.8 \%)$ were housewives, $66(8.7 \%)$ were a government employee, and 566(75 \%) had a monthly income of fewer than 30 US dollars (Table 1).

In relation to obstetric history, mostly the respondents get married for the first time between 15 and 18 years
$(60.3 \%), 56.6 \%$ reported their age at first pregnancy is 15-19 years (Table 2). Child marriage less than fifteen years were experienced by about $14 \%$ of the respondents. One hundred fifty-seven $(20.8 \%)$ of the women in the study sample was pregnant at the time of the survey and in terms of gravidity, $287(38 \%)$ of the respondents were gravida three-four. A little more than one half $(55 \%)$ of the women reported their desired number of children to be three-four, yet $33 \%$ women wished to have five or more than children (Table 2).

Table 1: Socio-demographic and economic characteristics of the respondents, 2015. $(n=755)$.

\begin{tabular}{|c|c|c|}
\hline Variables & & Frequency (\%) \\
\hline \multirow{6}{*}{ Age (years) } & $18-19$ & $115(15.2)$ \\
\hline & $20-25$ & $164(21.7)$ \\
\hline & $26-29$ & $167(22.1)$ \\
\hline & $30-34$ & $173(22.9)$ \\
\hline & $35-40$ & $120(15.9)$ \\
\hline & $>40$ & $16(2.1)$ \\
\hline \multirow{3}{*}{ Religion } & Orthodox & $504(66.8)$ \\
\hline & Protestant & $222(29.4)$ \\
\hline & Others ${ }^{1}$ & $29(3.8)$ \\
\hline \multirow{2}{*}{ Residence } & Rural & $653(86.5)$ \\
\hline & Urban & $102(13.5)$ \\
\hline \multirow{3}{*}{ Educational status } & $\begin{array}{l}\text { No formal } \\
\text { education }\end{array}$ & $426(56.4)$ \\
\hline & $\begin{array}{l}\text { Primary } \\
\text { education }\end{array}$ & $198(26.2)$ \\
\hline & $\begin{array}{l}\text { Secondary } \\
\text { education or } \\
\text { higher }\end{array}$ & 131 (17.4) \\
\hline \multirow{5}{*}{ Occupation } & Housewife & $444(58.8)$ \\
\hline & Farmer & $166(22.0)$ \\
\hline & $\begin{array}{l}\text { Government } \\
\text { employee }\end{array}$ & $66(8.7)$ \\
\hline & Student & $55(7.3)$ \\
\hline & Others & $24(3.2)$ \\
\hline \multirow{4}{*}{$\begin{array}{l}\text { Monthly income in } \\
\text { Birr }\end{array}$} & $<=260$ & $176(23.3)$ \\
\hline & $261-460$ & 149 (19.7) \\
\hline & $461-900$ & 241 (31.9) \\
\hline & $>900$ & $189(25.0)$ \\
\hline
\end{tabular}

Given that unintended pregnancy has resulted from the lack of access or availability of family planning, this study assessed participants' knowledge and attitude towards family planning.

Concerning family planning, more than one family planning methods were being known by 585 (77.9) of the study participants, $69 \%$ were current users of any type of contraception and by type of contraception methods; injectable accounts 439 (84\%) followed by implants 44 (9\%) and pills $25(5 \%)$ (Table 3$)$.

The need for more children has expressed more often as a reason for not using family planning. Nearly two percent 
of the respondents reported that they ever had experienced induced abortion, which has an implication in the existence of unintended pregnancy resulted in whether unsafe abortion or other unnecessary costs.

Table 2: Reproductive related characteristics of respondents in Bita Woreda, $2015(n=755)$.

\begin{tabular}{|c|c|c|}
\hline \multicolumn{2}{|l|}{ Variables } & Frequency (\%) \\
\hline \multirow{3}{*}{$\begin{array}{l}\text { Ideal number of } \\
\text { children }\end{array}$} & $1-2$ & $85(11.7)$ \\
\hline & $3-4$ & $399(55.0)$ \\
\hline & 5 and above & $241(33.2)$ \\
\hline \multirow{4}{*}{$\begin{array}{l}\text { Number of live } \\
\text { births (parity) }\end{array}$} & $1-2$ & $261(34.6)$ \\
\hline & $3-4$ & $275(36.4)$ \\
\hline & $5-6$ & $147(19.5)$ \\
\hline & $>6$ & $72(9.5)$ \\
\hline \multirow{3}{*}{$\begin{array}{l}\text { Age at first } \\
\text { pregnancy (years) }\end{array}$} & $<18$ & $151(20.0)$ \\
\hline & $18-20$ & $427(56.6)$ \\
\hline & $>21$ & $177(23.4)$ \\
\hline \multirow{4}{*}{$\begin{array}{l}\text { Age at first } \\
\text { marriage (years) }\end{array}$} & $<15$ & $107(14.2)$ \\
\hline & $15-18$ & $296(39.2)$ \\
\hline & $19-20$ & $235(31.1)$ \\
\hline & $>20$ & $117(15.5)$ \\
\hline \multirow{2}{*}{$\begin{array}{l}\text { History of } \\
\text { unintended } \\
\text { pregnancy in the } \\
\text { last three years* }\end{array}$} & One & $244(86.8)$ \\
\hline & Two & $31(13.2)$ \\
\hline \multirow{4}{*}{$\begin{array}{l}\text { Consequences of } \\
\text { the unintended } \\
\text { pregnancy }\end{array}$} & $\begin{array}{l}\text { Attempted to } \\
\text { stop it and fail }\end{array}$ & $30(10.6)$ \\
\hline & $\begin{array}{l}\text { Attempted to } \\
\text { stop it and } \\
\text { success }\end{array}$ & $12(4.0)$ \\
\hline & $\begin{array}{l}\text { Had ended in } \\
\text { stillbirth }\end{array}$ & $4(1.4)$ \\
\hline & $\begin{array}{l}\text { Has ended in } \\
\text { live birth }\end{array}$ & $229(83.3)$ \\
\hline \multirow{4}{*}{$\begin{array}{l}\text { Ideal number of } \\
\text { children }\end{array}$} & $1-2$ & 85 (11.3) \\
\hline & $3-4$ & 399 (52.9) \\
\hline & $5-6$ & $227(30.1)$ \\
\hline & $>6$ & $44(5.8)$ \\
\hline \multirow{4}{*}{$\begin{array}{l}\text { Number of } \\
\text { pregnancies } \\
\text { (Gravida) }\end{array}$} & $1-2$ & $249(33.0)$ \\
\hline & $3-4$ & $287(38.01)$ \\
\hline & $5-6$ & $162(21.5)$ \\
\hline & $>6$ & $57(7.6)$ \\
\hline \multirow{2}{*}{$\begin{array}{l}\text { Ever had induced } \\
\text { abortion }\end{array}$} & Yes & $13(2.0 \%)$ \\
\hline & No & $742(98.0 \%)$ \\
\hline
\end{tabular}

Four hundred sixteen (55\%) of the participants had listened to the radio or watched television regarding access to health services and $173(30 \%)$ had to walk greater than 1 hour to get family planning service. It is stated that 231 (31\%) had no discussion about family planning issues. Four hundred eighty-two (64\%) of the study sample had discussed the number of children they want to have with their spouse (Table 3 ).

Travel time to access the health facility is crucial for a woman to use the service provided, 173 (23\%) women had to travel more than one hour on foot to get family planning service (Table 3).

Table 3: Family planning knowledge and practice in Bita woreda, 2015, $(n \neq 755)$.

\begin{tabular}{|c|c|c|}
\hline \multicolumn{2}{|l|}{ Variables } & Frequency (\%) \\
\hline \multirow{2}{*}{$\begin{array}{l}\text { Knowledge of } \\
\text { family planning } \\
\text { methods }\end{array}$} & $\begin{array}{l}\text { More than } \\
\text { one method }\end{array}$ & 585 (77.9) \\
\hline & $\begin{array}{l}\text { One method } \\
\text { only }\end{array}$ & $166(22.1)$ \\
\hline \multirow{3}{*}{$\begin{array}{l}\text { Contraceptive } \\
\text { practice }\end{array}$} & current users & $521(69.0)$ \\
\hline & Ever used & $162(21.5)$ \\
\hline & Never Used & $72(9.5)$ \\
\hline \multirow{4}{*}{$\begin{array}{l}\text { Currently use } \\
\text { contraceptives }\end{array}$} & Pills & $25(4.8)$ \\
\hline & Injectables & $439(84.3)$ \\
\hline & Implants & $44(8.5)$ \\
\hline & Others $^{1}$ & $13(2.4)$ \\
\hline \multirow{2}{*}{$\begin{array}{l}\text { Discussion with } \\
\text { spouse on family } \\
\text { planning issues }\end{array}$} & Yes & $524(69.4)$ \\
\hline & No & $231(30.6)$ \\
\hline \multirow{2}{*}{$\begin{array}{l}\text { Discussion with } \\
\text { spouse on number } \\
\text { of children }{ }^{1}\end{array}$} & Yes & $482(63.8)$ \\
\hline & No & 224 (29.7) \\
\hline \multirow{2}{*}{$\begin{array}{l}\text { Exposure to mass } \\
\text { media such } \\
\text { (TV/Radio) }\end{array}$} & Yes & $416(55.1)$ \\
\hline & No & $339(44.9)$ \\
\hline \multirow{3}{*}{$\begin{array}{l}\text { Travel time to } \\
\text { family planning } \\
\text { service provider }\end{array}$} & $\begin{array}{l}\text { Less than } 30 \\
\text { minutes }\end{array}$ & $297(39.3)$ \\
\hline & $\begin{array}{l}30-60 \\
\text { minute }\end{array}$ & $285(37.7)$ \\
\hline & $\begin{array}{l}\text { Greater than } \\
1 \text { hour }\end{array}$ & 173 (22.9) \\
\hline
\end{tabular}

${ }^{1}$ For those who had husband or partner

Table 4 presents the result of the cross-tabulation percentages of socio-demographic characteristics with unwanted and unplanned pregnancies. A very important profile can be observed when comparing the women who wanted to be pregnant at that time and those reporting a mistimed or unwanted pregnancy. Most women who had no experienced unplanned or unintended pregnancies are in the aged 30-34 (Table 4).

Relatively the higher income category has less number of women who experienced both unwanted and unintended pregnancy. Women in the age group of 18-20 and had no formal education had a higher percentage of having unintended pregnancies.

Whereas unplanned and unwanted pregnancies were higher among women who had 3-4 births and statistically shows an association (Table 4). Relatively high percentage of those reporting unwanted pregnancy was reported by housewives $(54 \%)$ (Table 4$)$.

The multivariate analysis adjusted for each block of variables that maintained a significant association with at least one category under analysis for mistimed or 
unwanted pregnancy were entered into the bivariate model. value of 0.25 and less were fitted into multiple logistic regression models.

Factors that are associated with unintended pregnancy on bivariate analysis using enter method at the level of P-

Table 4: Current pregnancy of the unplanned pregnancy and unwanted pregnancy, Bita woreda, 2015. $(n=275)$.

\begin{tabular}{|c|c|c|c|c|}
\hline \multirow{2}{*}{ Variables } & \multicolumn{2}{|c|}{ Unplanned pregnancy } & \multicolumn{2}{|c|}{ Unwanted pregnancy } \\
\hline & Frequency (\%) & p-value & Frequency (\%) & p-value \\
\hline \multicolumn{4}{|l|}{ Age (years) } & \multirow{6}{*}{$\mathrm{p}=0.063$} \\
\hline $18-20$ & $13(14.8)$ & \multirow{5}{*}{$\mathrm{p}=0.138$} & $19(21.6)$ & \\
\hline $20-25$ & $16(10.9)$ & & $25(17.1)$ & \\
\hline $26-29$ & $30(19.1)$ & & $40(25.5)$ & \\
\hline $30-34$ & $34(20.1)$ & & $51(31.1)$ & \\
\hline 35 and above & $18(14.0)$ & & $29(22.7)$ & \\
\hline \multicolumn{2}{|l|}{ Monthly income } & \multirow{5}{*}{$\mathrm{p}=0.220$} & & \multirow{5}{*}{$\mathrm{p}=0.060$} \\
\hline$<=260$ & $25(15.9)$ & & $38(24.2)$ & \\
\hline $261-460$ & $31(23.3)$ & & $43(32.3)$ & \\
\hline $461-900$ & $37(17.1)$ & & $49(22.6)$ & \\
\hline$>900$ & $18(10.2)$ & & $34(19.3)$ & \\
\hline \multicolumn{2}{|l|}{ Educational status } & \multirow{4}{*}{$\mathrm{p}=0.090$} & & \multirow{4}{*}{$\mathrm{p}=0.052$} \\
\hline Had no formal education & $72(18.2)$ & & $108(27.3)$ & \\
\hline Primary school completed & $27(16.3)$ & & $34(20.5)$ & \\
\hline Secondary and above & $12(9.8)$ & & $22(18.0)$ & \\
\hline \multicolumn{2}{|l|}{ Occupational status } & \multirow{6}{*}{$\mathrm{p}=0.006$} & & \multirow{6}{*}{$\mathrm{p}=0.140$} \\
\hline Farmer & $35(22.3)$ & & $48(30.6)$ & \\
\hline Government employee & $2(3.0)$ & & $10(15.2)$ & \\
\hline Student & $3(15.0)$ & & $5(25.0)$ & \\
\hline Housewife & $70(16.7)$ & & $97(23.0)$ & \\
\hline Others ${ }^{* *}$ & $1(5.0)$ & & $4(20.0)$ & \\
\hline \multicolumn{2}{|l|}{ Number of live births } & \multirow{5}{*}{$\mathrm{p}=0.003$} & & \multirow{5}{*}{$\mathrm{p}=0.003$} \\
\hline $1-2$ & $30(12.3)$ & & $46(18.9)$ & \\
\hline $3-4$ & $42(15.9)$ & & $62(23.5)$ & \\
\hline $5-6$ & $25(18.5)$ & & $39(28.9)$ & \\
\hline$>6$ & $14(35.0)$ & & $17(42.5)$ & \\
\hline \multicolumn{2}{|c|}{ Age at first pregnancy (yrs) } & \multirow{4}{*}{$\mathrm{p}=0.014$} & & \multirow{4}{*}{$\mathrm{p}=0.007$} \\
\hline$<18$ & $32(23.4)$ & & $45(32.9)$ & \\
\hline $18-20$ & $62(15.9)$ & & $92(23.7)$ & \\
\hline$>21$ & $17(10.8)$ & & $27(17.1)$ & \\
\hline \multicolumn{2}{|l|}{ Age at first marriage (yrs) } & \multirow{5}{*}{$\mathrm{p}=0.041$} & & \multirow{5}{*}{$\mathrm{p}=0.263$} \\
\hline$<15$ & $19(17.9)$ & & $25(23.6)$ & \\
\hline $15-18$ & $44(15.6)$ & & $72(25.4)$ & \\
\hline $19-20$ & $43(20.0)$ & & $55(25.6)$ & \\
\hline$>20$ & $5(6.3)$ & & $12(15.2)$ & \\
\hline
\end{tabular}

The final model, factors associated with unintended pregnancy is presented in Table 5.

The following variables attain an association: travel time to the family planning service provider more than 60 minutes $\quad(\mathrm{AOR}=2.23 \quad(1.37-3.63)$; being ever contraceptive user, but not currently $(\mathrm{AOR}=1.77$ (1.182.67); being never use modern contraceptive ( $\mathrm{AOR}=2.43$ (1.22-4.86); and women with parity of five and above $(\mathrm{AOR}=5.52$ (2.50-12.20) (Table 5).

\section{DISCUSSION}

The results of this study suggest that the study area has a high prevalence of unintended pregnancy, 36.5\%, compared to the national average. ${ }^{10}$ Splitting into mistimed and unwanted pregnancies, it accounts, $26 \%$ and $10.5 \%$ respectively. It is lower than the verdict from a study conducted in Southern Ethiopia, which is $42.4 \%$ (10.5\% mistimed and $31.8 \%$ unwanted). ${ }^{9}$ This observed difference could be due to that this study considers pregnancies which resulted only in live birth, though both 
generated data, primarily through interviews from most recent pregnancy occurred five years back from the survey; however, it is in line with the other research findings, $32 \%$ (21\% mistimed and $11 \%$ unwanted). ${ }^{11}$ Compare to other countries in East Africa, the current study finding is also lower than a study from Tanzania, $45.9 \%$ (32.5\% mistimed and $13.4 \%$ unwanted). ${ }^{15}$ The difference could be because of differences in sociocultural factors.

Table 5: Factors associated with unintended pregnancy among ever-pregnant women in, Bita woreda, 2015. $(\mathbf{n}=\mathbf{2 7 5})$.

\begin{tabular}{|c|c|c|c|c|c|}
\hline \multirow{2}{*}{ Variables } & \multirow{2}{*}{ Categories } & \multicolumn{4}{|c|}{ Unintended pregnancy } \\
\hline & & Yes & No & COR $(95 \% \mathrm{CI})$ & $\operatorname{AOR}(95 \% \mathrm{CI})$ \\
\hline \multirow{2}{*}{ Place of residence } & Urban & 27 & 75 & 1 & 1 \\
\hline & Rural & 248 & 405 & $1.70(1.07,2.71)$ & $1.31(0.70-2.44)$ \\
\hline \multirow{2}{*}{ Exposure to media } & No & 148 & 191 & 1 & 1 \\
\hline & Yes & 127 & 289 & $0.57(0.42-0.77)$ & $0.90(0.59-1.35)$ \\
\hline \multirow{3}{*}{$\begin{array}{l}\text { Travel time to get } \\
\text { family planning service } \\
\text { (minute) }\end{array}$} & $<30$ & 78 & 219 & 1 & 1 \\
\hline & $30-60$ & 100 & 185 & $1.518(1.06-2.16)$ & $1.04(0.68-1.60)$ \\
\hline & $>60$ & 97 & 76 & $3.58(2.41-5.33)$ & $2.23(1.37-3.63)^{*}$ \\
\hline \multirow{3}{*}{$\begin{array}{l}\text { Modern contraceptive } \\
\text { practice }\end{array}$} & Current use & 157 & 364 & 1 & 1 \\
\hline & Ever use & 64 & 98 & $1.51(1.05-2.18)$ & $1.77(1.18-2.67)^{*}$ \\
\hline & Never used & 54 & 18 & $6.96(3.95-12.24)$ & $2.43(1.22-4.86)^{*}$ \\
\hline \multirow{3}{*}{ Age (years) } & $<20$ & 52 & 63 & 1 & 1 \\
\hline & $20-34$ & 167 & 337 & $0.60(0.40-0.91)$ & $0.92(0.48-1.74)$ \\
\hline & $\geq 35$ & 56 & 80 & $0.85(0.51-1.40)$ & $1.03(0.49-2.17)$ \\
\hline \multirow{2}{*}{ Marital status } & In marital union & 190 & 416 & 1 & 1 \\
\hline & Not in a marital union & 85 & 64 & $2.91(2.02-4.20)$ & $1.39(0.89-2.16)$ \\
\hline \multirow{3}{*}{ Educational status } & No formal education & 166 & 260 & 1 & 1 \\
\hline & Primary & 73 & 125 & $0.92(0.65-1.30)$ & $0.89(0.56-1.40)$ \\
\hline & Secondary and above & 36 & 95 & $0.59(0.39-0.91)$ & $0.91(0.48-1.70)$ \\
\hline \multirow{3}{*}{$\begin{array}{l}\text { Parity } \\
\text { (number of live births) }\end{array}$} & One & 37 & 94 & 1 & 1 \\
\hline & Two -four & 152 & 287 & $1.35(0.88-2.07)$ & $2.27(1.21-4.23)^{*}$ \\
\hline & Five and above & 86 & 99 & $2.21(1.37-3.56)$ & $5.52(2.50-12.20)^{*}$ \\
\hline
\end{tabular}

Most recent research among women in the Oromia region, Ethiopia found that travel time is not associated with unintended pregnancy, though as mentioned in the result section it has shown an association especially for those who traveled more than one hour to get family planning service. ${ }^{11}$

This may be due to more distance interferes with better access to family planning and hence leading to the increased occurrence of unintended pregnancy. In terms of associated factors, unintended pregnancy in this sample was predominantly more likely to women who never used a modern contraceptive, were more than two times more likely to have an unintended pregnancy. This is in line with a study from Southwest Ethiopia. ${ }^{12}$

This abides by the reality that unintended pregnancies can be prevented with the effective use of contraceptives, but a study from Jordan contradict to this modern contraceptive users were more likely to report unintended pregnancies than non-users (21 percent compared with 15 percent). ${ }^{20,22}$

This variation may be due to those who use contraceptives might have higher expectations about control over their fertility and timing as a result more likely to view a pregnancy unintended. The other explanation could be those women who use a contraceptive has more chance of reporting than women who ever had no exposure to family planning services and contextual factors.

Unintended pregnancy has been linked to many factors, including, parity where women with five and above were more likely experience an unintended pregnancy than with low parity. This is in alignment with findings from Tanzania and rural Gahanna. ${ }^{15,23}$

These may be explained by the fact that every additional birth increases the risk of unintended pregnancy and also such women are likely to reach their desired fertility and regarded any additional birth coming to them as unintended. Moreover, the need for more children and less practicing of family planning could lead her to experience an unintended pregnancy.

In addition to all those factors, the number of children alive birth the women had is also associated with unintended pregnancy. Women with five and above children were more likely to practice an unintended 
pregnancy. This is in line with the finding from Hossana town, Southern Ethiopia, and from Oromia region, Ethiopia. ${ }^{11,13}$

This could be due to with increased desire for children those pregnancies are less classified as unintended in the rural community children are taken as an asset and treasure of the family, $(86 \%)$ of the current participant are from a rural community.

As respondents were retrospectively asked about their pregnancy intentions, this may cause recall bias. In this study pregnancies not resulting in a live birth were not taken into account constitutes a source of bias. Those pregnancies that end up in abortion are likely to be unwanted/mistimed and thus the true prevalence of unintended pregnancy is likely to be higher than the findings shown here. The study was also cross-sectional, a design which limits causal inferences because of their snapshot nature though, efforts are made to collect relabel data as much as possible.

\section{CONCLUSION}

Compared to the national average the overall magnitude of unintended pregnancy in the study area was high. Travel time to get family planning service and ever practicing contraceptives and the number of live births a woman had were found the most important factors.

Based on the findings from this study, increasing access to family planning services and empowering women to practice contraceptives are some of the factors that would help to reduce unintended pregnancy because as the contraceptive service is more accessible, women would be protected from risks of pregnancy-related morbidity and mortality.

Further research using the mixed method, qualitative as well quantitative especially longitudinal data could benefit in exploring community factors related to unintended pregnancy and contraceptive discontinuation as women reported of ever use but failing to continue as most of them reported that they were not current users.

\section{ACKNOWLEDGMENTS}

Authors would like to thank all studied participants.

\section{Funding: We thank Jimma University for funding Conflict of interest: None declared}

Ethical approval: The study received ethical clearance from Ethical Review Committee of Jimma University; College of Public Health and Medical Sciences. Support letter was obtained from health and administrative offices at the different level in the study area. Verbal consent was obtained from study participants and those who were in need of detail information and service referred to the nearest health facility.

\section{REFERENCES}

1. Santelli J. Rochat R, Hatfield-Timajchy K, Gilbert $\mathrm{BC}$, Curtis K, et al. The measurement and meaning of unintended pregnancy. Perspect Sexual Reprod Health, 2003. 35(2):94-101.

2. Haddad LB, Nour NM. Unsafe abortion: unnecessary maternal mortality. Rev Obstet Gynecol. 2009;2(2):122.

3. Grimes DA, Benson J, Singh S, Romero M, Ganatra B, Okonofua FE, Shah IH. Unsafe abortion: the preventable pandemic. Lancet. 2006;368(9550):1908-19.

4. World Health Organization Trends in maternal mortality: 1990 to 2015: estimates by WHO, UNICEF, UNFPA, World Bank Group and the United Nations Population Division. 2015: Geneva, Switzerland.

5. World Health Organization. unsafe abortion, global and regional estimates of incidence of mortality due to unsafe abortion with a listing of available country data. 2004: Geneva, Switzerland.

6. Gipson JD, Koenig MA, Hindin MJ. The effects of unintended pregnancy on infant, child, and parental health: a review of the literature. Studies Fam Planning. 2008;39(1):18-38.

7. Central Statistical Agency Ethiopia, Ethiopia Demographic and Health Survey 2011, C.S.A.a.I. International, Editor. 2011: Addis Ababa, Ethiopia and Calverton, Maryland, USA.

8. Singh S, Fetters T, Gebreselassie H, Abdella A, Gebrehiwot Y, Kumbi S, et al. The estimated incidence of induced abortion in Ethiopia, 2008. Int Perspectives Sexual Reprod Jealth. 2010:16-25.

9. Geda NR, Lako TK. A population based study on unintended pregnancy among married women in a district in Southern Ethiopia. J Geography Regional Plann. 2011;4(7):417-27.

10. Central Stastical Agency Ethiopia, Ethiopia Demographic and Health Survey 2011, M. Calverton, USA: Central Statistical Agency and ICF International Editor. 2012: Addis Ababa, Ethiopia.

11. Teshome FT, Hailu AG, Teklehaymanot AN. Prevalence of unintended pregnancy and associated factors among married pregnant women in Ganji Woreda, West Wollega Oromia Region, Ethiopia. Sci J Public Health, 2014. 2(2):92-101.

12. Dibaba Y, Fantahun M, Hindin MJ. The association of unwanted pregnancy and social support with depressive symptoms in pregnancy: evidence from rural Southwestern Ethiopia. BMC Preg Childbirth. 2013;13(1):135.

13. Hamdela B, Tilahun T. Unwanted pregnancy and associated factors among pregnant married women in Hosanna Town, Southern Ethiopia. PloS one. 2012;7(6):e39074.

14. Central Statistical Agency [Ethiopia] and ORC Macro, Ethiopia demographic and health survey 2005. C.S.A.E.a.O. Macro, Editor. 2006: Addis Ababa and Maryland. 
15. Exavery A, Kanté AM, Njozi M, Tani K, Doctor HV, Hingora A, Phillips JF. Predictors of mistimed, and unwanted pregnancies among women of childbearing age in Rufiji, Kilombero, and Ulanga districts of Tanzania. Reprod Health. 2014;11(1):63.

16. Central Statistical Agency (Ethiopia) and ORC Macro, Ethiopia demographic and health survey 2000, C.S.A.E.a.O. Macro, Editor. 2001: Addis Ababa and Maryland.

17. Population Census Commission, The 2007 population and housing census of ethiopia: statistical report at national level, 2008, Office of the population and housing census commission, Federal Democratic Republic of Ethiopia: Addis Ababa.

18. Wado YD, Afework MF, Hindin MJ. Unintended pregnancies and the use of maternal health services in southwestern Ethiopia. BMC Int Health Hum Rights. 2013;13(1):36.

19. Tebekaw Y, Aemro B, Teller C. Prevalence and determinants of unintended childbirth in Ethiopia. BMC Preg Childbirth. 2014;14(1):326.
20. Blumenthal PD, Voedisch A, Gemzell-Danielsson K. Strategies to prevent unintended pregnancy: increasing use of long-acting reversible contraception. Hum Reprod Update. 2010;17(1):12137.

21. Tsui AO, McDonald-Mosley R, Burke AE. Family planning and the burden of unintended pregnancies. Epidemiologic Rev. 2010;32(1):152-74.

22. Eggleston E, Tsui AO, Kotelchuck M. Unintended pregnancy and low birthweight in Ecuador. Am J Public Health. 2001;91(5):808.

23. Singh S, Darroch JE. Adding It Up: Costs and benefits of contraceptive services, G.I.A. UNFPA, Editor;2012.

Cite this article as: Mulugeta S, Tilahun T, Admasu B. More young adults accidentally pregnant; neither timed nor wanted: evidence from Southwest Ethiopia. Int J Reprod Contracept Obstet Gynecol 2018;7:3459-66. 